\title{
Triplet chemotherapy with paclitaxel, gemcitabine, and cisplatin as second-line therapy for advanced urothelial carcinoma
}

\author{
Hideki Takeshita ${ }^{{ }^{*}}$, Koji Chiba $^{1}$, Sachi Kitayama ${ }^{1}$, Shingo Moriyama ${ }^{1}$, Rika Omura ${ }^{2}$, \\ Akira Noro ${ }^{1}$ \\ ${ }^{1}$ Department of Urology, Saitama Red Cross Hospital, Saitama, Japan; ${ }^{*}$ Corresponding Author: take uro@ybb.ne.jp \\ ${ }^{2}$ Department of Pharmacy, Saitama Red Cross Hospital, Saitama, Japan
}

Received 11 November 2012; revised 12 December 2012; accepted 11 January 2013

\begin{abstract}
Background: Methotrexate, vinblastine, doxorubicin, and cisplatin regimen, and gemcitabine and cisplatin regimen are widely used for advanced or metastatic urothelial carcinomas (UCs). However, a standard treatment for patients who fail these first-line chemotherapies is unavailable. We examined the efficacy and safety of secondline paclitaxel, gemcitabine, and cisplatin (PCG) chemotherapy in Japanese patients. Methods: Between 2004 and 2010, 25 patients with metastatic UCs who failed to respond to platinumbased regimens were treated with PCG. They received intravenous paclitaxel $\left(60 \mathrm{mg} / \mathrm{m}^{2}\right)$ and gemcitabine $\left(1000 \mathrm{mg} / \mathrm{m}^{2}\right)$ on days 1 and 8 , and cisplatin $\left(70 \mathrm{mg} / \mathrm{m}^{2}\right)$ on day 2 of every 21 -day course. We retrospectively collected patients' clinical and pathological data and evaluated adverse effects and survivals. Results: Patients underwent 95 PCG cycles in all (average, 3.8 cycles per patient). One patient (4\%) achieved complete response, $5(20 \%)$ showed partial response, 8 (42\%) had disease stabilization, and $5(26 \%)$ had disease progression. Median overall survival was 8.5 months. Neutropenia and thrombocytopenia of grade $\geq 3$ were observed in $68 \%$ and $56 \%$ of patients, respectively. No treatment-related death occurred. Multivariate analysis revealed that hemoglobin levels $<10 \mathrm{~g} / \mathrm{dL}$ and estimated glomerular filtration rate $<60 \mathrm{~mL} /$ $\left(\min \cdot 1.73 \mathrm{~m}^{2}\right)$ were significant risk factors for overall survival. Conclusion: PCG chemotherapy in the second-line setting potentially con- tributed to good prognosis in selected patients with relatively significant but tolerable toxicity.
\end{abstract}

Keywords: Metastatic Urothelial Carcinoma; Second-Line; Paclitaxel; Gemcitabine

\section{INTRODUCTION}

In patients with advanced or metastatic urothelial cancers (UCs), combination chemotherapy with methotrexate, vinblastine, doxorubicin, and cisplatin (M-VAC) was frequently used as standard treatment $[1,2]$. Although the tumor response rate after M-VAC administration was about $40 \%-70 \%$, the long-term survival rate was poor at approximately $3.7 \%$ and was associated with substantial toxicity $[1,2]$. Combination chemotherapy with gemcitabine and cisplatin (GC) has been demonstrated to be equally effective and less toxic than M-VAC [3]. Since then, GC has been largely used as the standard first-line chemotherapy together with M-VAC for advanced UCs.

Because the response to first-line chemotherapy is short-lived, various second-line chemotherapy regimens have been studied. Paclitaxel and gemcitabine combined regimen is one of the most promising ones, as recent studies have reported a good response rate and relatively long survival [4-7]. Vinflunine monotherapy is another promising regimen with moderate efficacy and mild toxicity $[8,9]$. However, the benefit of these second-line chemotherapy regimens has not been fully demonstrated, and no standard second-line regimens have been established so far.

In order to establish a more effective regimen for advanced UCs, Bellmunt et al., developed a triplet first-line chemotherapy regimen of paclitaxel, gemcitabine, and cisplatin (PCG) and achieved an excellent response rate of $78 \%$ with median overall survival of 24 months [10]. Moreover, a recent randomized trial showed that PCG in a first-line chemotherapy setting provided a higher response rate and 3 months survival benefit, although that was not significantly different compared to that for GC [11]. However, the PCG regimen in a second-line setting has not yet been analyzed.

We, therefore, investigated the efficacy and safety of PCG as second-line chemotherapy regimen after failure of cisplatin-based treatment. 


\section{PATIENTS AND METHODS}

\subsection{Patients}

We administered PCG to 25 patients with advanced UC after failure of first-line cisplatin-based regimen between 2004 and 2010 at Saitama Red Cross Hospital, which is one of regional cancer treatment centers designnated by the Ministry of Health, Labour and Welfare of Japan since 2005 and is able to provide standard cancer care for regional patients. We obtained written informed consent from all patients before their treatment. PCG was given to the patients who met the following criteria: locally advanced (extending beyond the primary organs) or metastatic cancer, histologically confirmed UC originnating from the renal pelvis, ureter, or bladder with measurable lesions; received at least 1 course of cisplatin-based chemotherapy; below 80 years of age with life expectancy of 3 months or more; Eastern Cooperative Oncology Group performance status (ECOG-PS) $\leq 2$; absolute granulocyte count $\leq 1500 / \mathrm{mm}^{3}$; absolute platelet count $\leq 100,000 / \mathrm{mm}^{3}$; serum creatinine level $\leq 1.5 \mathrm{mg} / \mathrm{dL}$; and serum bilirubin level $\leq 2 \mathrm{mg} / \mathrm{dL}$. We retrospectively collected clinical and pathological data based on patients' records and evaluated treatment courses, adverse effects, and survivals. We calculated the modified CharlsonRomano index to evaluate pre-treatment comorbidity [12, 13]. Estimated glomerular filtration rate (eGFR) was calculated using the formula developed for Japanese patients [14]. This study was approved by the institutional review board of Saitama Red Cross Hospital.

\subsection{Chemotherapy Regimens}

The specific dose and schedule of PCG were determined by modifying a previously reported regimen [10]. Paclitaxel was administered at a dose of $60 \mathrm{mg} / \mathrm{m}^{2}$ on days 1 and 8 , and cisplatin at a dose of $70 \mathrm{mg} / \mathrm{m}^{2}$ on day 2 of every 3 -week cycle. If absolute granulocyte count was less than $1500 / \mathrm{mm}^{3}$ at the initiation of the subsequent cycles, the treatment was delayed until granulocyte count recovered. Diphenhydramine $(50 \mathrm{mg})$, ranitidine $(50 \mathrm{mg})$, and dexamethasone $(20 \mathrm{mg})$ were administered $30 \mathrm{~min}$ before paclitaxel infusion on days 1 and 8 , as premedication to prevent paclitaxel-associated hypersensitivity reaction. To prevent nausea and emesis, granisetron hydrochloride $(3 \mathrm{mg})$ and dexamethasone $(8$ $\mathrm{mg}$ ) were given $30 \mathrm{~min}$ before cisplatin infusion on day 2 . Toxicity was graded according to the National Cancer Institute Common Toxicity Criteria version 2.0. An intial dose reduction for all drugs was performed according to creatinine clearance (Ccr) or ECOG-PS values. A 20\% reduction in the dose was performed if $\mathrm{Ccr}$ was lower than $60 \mathrm{~mL} / \mathrm{min}$ or if ECOG-PS was $\leq 1$. If patients reported one of the following effects: grade 4 neutropenia for more than 3 days, grade 3 febrile neutronpenia, grade
$3 / 4$ thrombocytopenia, or nonhematologic toxicity grade $3 / 4$, a secondary dose reduction of $20 \%$ for all 3 drugs was made for the following cycles. Once reduced, the doses were not escalated.

\subsection{Treatment Evaluation}

Physical examination and imaging studies were performed every 2 cycles to examine patients' responses, which was evaluated retrospectively according to the Response Evaluation Criteria in Solid Tumors guidelines [15].

\subsection{Statistical Analyses}

Overall survival was defined as the interval between the start of PCG chemotherapy and patient death and was estimated using the Kaplan-Meier method. A log-rank test was used to analyze differences in the survival curves. Pretreatment prognostic factors for overall survival were assessed using Cox proportional hazards model. Identified independent prognostic factors were examined whether they were related to the cycles and amount of the chemotherapy actually administered using the Wilcoxon rank sum test. Differences with $p<0.05$ were considered statistically significant. Statistical analyses were performed using JMP ${ }^{\circledR}$ 7.0.2 (SAS Institute, Cary, NC, USA).

\section{RESULTS}

\subsection{Patient Characteristics}

Patient characteristics are shown in Table 1. Threequarters of all patients were men. Twenty-one (84\%) had ECOG-PS of 0 and $18(72 \%)$ had a Charlson-Romano Index score of 0 . Twenty patients $(80 \%)$ underwent $\mathrm{M}$ VAC prior to PCG, and the remaining $5(20 \%)$ received another cisplatin-based regimen (e.g., a combination regimen with ifosfamide, 5-fluorouracil, etoposide, and cisplatin $[16,17])$. The primary tumors were more frequently located in the upper urinary tract $(60 \%)$ than in the urinary bladder $(40 \%)$. At the histological examination, 19 primary tumors were pure $(76 \%)$ and 6 were mixed (24\%) UCs. The disease sites were distributed as follows: pelvis, 5 (locally advanced extending beyond the urinary bladder, 1 and local recurrence after cystectomy in the pelvis, 4); lungs, 16; lymph nodes, 13; liver, 5; bone, 12; and pancreas, 1 . In 19 (76\%) patients, the disease was present in 2 or more sites, and $21(84 \%)$ presented visceral metastases.

\subsection{Treatment Efficacy}

In all, 95 cycles of PCG were performed with an average of 3.8 cycles per patient. Dose reductions were required in 72 cycles $(76 \%)$. Overall response rates are 
Table 1. Patient characteristics.

\begin{tabular}{|c|c|c|}
\hline Characteristics & \multicolumn{2}{|c|}{ No. of patients (\% or IQR) } \\
\hline Patients & 25 & \\
\hline Age (years) & 64 & $(59-71)$ \\
\hline \multicolumn{3}{|l|}{ Sex } \\
\hline Male & 20 & $(75)$ \\
\hline Female & 5 & $(25)$ \\
\hline \multicolumn{3}{|l|}{ ECOG performance status } \\
\hline 0 & 21 & $(84)$ \\
\hline 1 & 3 & (12) \\
\hline$\geq 2$ & 1 & (4) \\
\hline \multicolumn{3}{|l|}{ Charlson-Romano Index score } \\
\hline 0 & 18 & $(72)$ \\
\hline$\geq 1$ & 7 & $(28)$ \\
\hline \multicolumn{3}{|l|}{ Previous chemotherapy regimen } \\
\hline M-VAC & 20 & $(80)$ \\
\hline Other cisplatin-based regimen & 5 & $(20)$ \\
\hline $\begin{array}{l}\text { Previous cumulative dose of cisplatin } \\
\text { (mg) }\end{array}$ & 200 & $(113-443)$ \\
\hline \multicolumn{3}{|l|}{ Previous definitive surgery } \\
\hline Presence & 17 & $(68)$ \\
\hline Absence & 8 & $(32)$ \\
\hline \multicolumn{3}{|l|}{ Primary organ } \\
\hline Bladder & 10 & $(40)$ \\
\hline Upper urinary tract & 15 & $(60)$ \\
\hline \multicolumn{3}{|l|}{ Histology } \\
\hline Pure UC & 19 & $(76)$ \\
\hline Mixed UC & 6 & $(24)$ \\
\hline \multicolumn{3}{|l|}{ Disease sites ${ }^{*}$} \\
\hline Pelvis & 5 & \\
\hline Lung & 16 & \\
\hline Lymph node & 13 & \\
\hline Liver & 5 & \\
\hline Bone & 12 & \\
\hline Pancreas & 1 & \\
\hline \multicolumn{3}{|l|}{ No. of sites of disease } \\
\hline 1 & 6 & (24) \\
\hline$\geq 2$ & 19 & (76) \\
\hline \multicolumn{3}{|l|}{ Visceral metastasis } \\
\hline Presence & 21 & $(84)$ \\
\hline Absence & 4 & (16) \\
\hline Hemoglobin (g/dL) & 11.2 & $(8.9-12.2)$ \\
\hline C-reactive protein $(\mathrm{mg} / \mathrm{L})$ & 21 & $(4-48)$ \\
\hline $\operatorname{Ccr}(\mathrm{mL} / \mathrm{min})$ & 61.8 & $(49.1-72.8)$ \\
\hline eGFR $\left(\mathrm{mL} /\left(\min \cdot 1.73 \mathrm{~m}^{2}\right)\right)$ & 53.4 & $(47.3-60.2)$ \\
\hline
\end{tabular}

IQR, interquartile range; ECOG, Eastern Cooperative Oncology Group; M-VAC, Methotrexate, vinblastine, doxorubicin, and cisplatin; UC, urothelial carcinoma; eGFR, estimated glomerular filtration rate, "duplication allowed. shown in Table 2. The response rate (complete response $(\mathrm{CR})+$ partial response (PR)) was $24 \%$, and the disease control rate (CR + PR + stable disease (SD)) was $56 \%$. Figure 1 shows a patient with good response in lung and bone metastases. All patients except 1 who was lost to follow-up soon after the treatment eventually relapsed and died.

\subsection{Toxicity}

Toxicity results are summarized in Table 3. The most significant toxic effect was myelosuppression. Moreover, we observed grade 3/4 neutropenia in 17 (68\%) patients, and granulocyte colony-stimulating factor injection was required in 11 patients $(44 \%)$. Grade 3 febrile neutropenia occurred in 6 patients (24\%), grade $3 / 4$ anemia in $15(60 \%)$ patients, and red blood cell transfusion was required in $4(16 \%)$. In addition, $14(56 \%)$ patients reported grade 3 thrombocytopenia and 6 of them required platelet concentrate transfusion. Although we observed severe grade 3 diarrhea, grade 3 skin rash, and grade 3 cerebrovascular ischemia in $4 \%$ of the patients ( 1 patient each), we managed these side effects successfully. There was no obvious treatment related-death throughout the entire treatment period.

Table 2. Best overall response.

\begin{tabular}{ccc}
\hline Response & No. of patients & (\%) \\
\hline CR & 1 & 4 \\
PR & 5 & 20 \\
SD & 8 & 32 \\
PD & 11 & 44 \\
Total & 25 & 100 \\
\hline
\end{tabular}

$\mathrm{CR}$, complete response; $\mathrm{PR}$, partial response; $\mathrm{SD}$, stable disease; $\mathrm{PD}$, progressive disease.

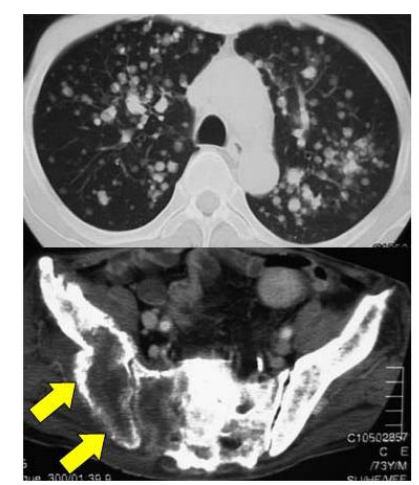

(a)

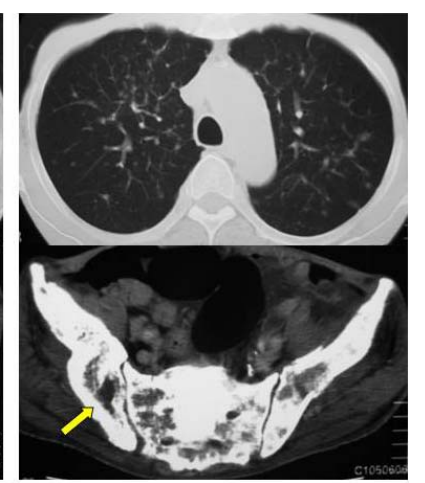

(b)
Figure 1. A case with good response to PCG in lung and bone metastases; (a) A 73-year-old man who had recurrences in the lung and bone after 2 cycles of M-VAC; (b) Three cycles of PCG dramatically reduced lung and bone metastases. 
Table 3. Toxicity of PCG after failure of platinum-based chemotherapy.

\begin{tabular}{|c|c|c|}
\hline Toxicity & No. of patients & $(\%)$ \\
\hline \multicolumn{3}{|l|}{ Neutropenia } \\
\hline Grade 3 & 7 & 28 \\
\hline Grade 4 & 10 & 40 \\
\hline Febrile neutropenia & 6 & 24 \\
\hline \multicolumn{3}{|l|}{ Thrombocytopenia } \\
\hline Grade 3 & 14 & 56 \\
\hline \multicolumn{3}{|l|}{ Anemia } \\
\hline Grade 2 & 5 & 20 \\
\hline Grade 3 & 9 & 36 \\
\hline Grade 4 & 6 & 24 \\
\hline \multicolumn{3}{|l|}{ Nausea } \\
\hline Grade 2 & 10 & 40 \\
\hline Grade 3 & 2 & 8 \\
\hline \multicolumn{3}{|l|}{ Diarrhea } \\
\hline Grade 2 & 1 & 4 \\
\hline Grade 3 & 1 & 4 \\
\hline \multicolumn{3}{|l|}{ Neuropathy } \\
\hline Grade 2 & 3 & 12 \\
\hline \multicolumn{3}{|l|}{ Skin rash } \\
\hline Grade 3 & 1 & 4 \\
\hline \multicolumn{3}{|c|}{ Cerebrovascular ischemia } \\
\hline Grade 2 & 1 & 4 \\
\hline Grade 3 & 1 & 4 \\
\hline \multicolumn{3}{|l|}{ Taste disturbance } \\
\hline Grade 2 & 1 & 4 \\
\hline \multicolumn{3}{|l|}{ Supportive drugs } \\
\hline $\mathrm{RBC}$ transfusion & 4 & 16 \\
\hline G-CSF infection & 11 & 44 \\
\hline $\mathrm{PC}$ transfusion & 6 & 24 \\
\hline
\end{tabular}

PCG, paclitaxel, cisplatin, and gemcitabine; RBC, red blood cell; G-CSF, granulocyte colony-stimulating factor; PC, platelet concentrate.

\subsection{Survival Analysis}

Median overall survival was 8.5 months $(95 \%$ confidence interval (CI), 5.3 - 13.6) (Figure 2). The one-year overall survival rate was $29 \%$. Univariate analysis revealed that presence of liver metastasis, hemoglobin $(\mathrm{Hb})$ level $<10 \mathrm{~g} / \mathrm{dL}$, and eGFR $<60 \mathrm{~mL} /\left(\min \cdot 1.73 \mathrm{~m}^{2}\right)$ were significant risk factors for overall survival. Multivariate analysis revealed two independent prognostic factors: $\mathrm{Hb}$ $<10 \mathrm{~g} / \mathrm{dL}$ (hazard ratio (HR), 4.08; 95\% CI, 1.51 - 11.19) and eGFR $<60 \mathrm{~mL} /\left(\min \cdot 1.73 \mathrm{~m}^{2}\right)(\mathrm{HR}, 2.83$; CI, 1.06 -

\subsection{1)(Table 4).}

When patients were stratified into 3 groups according to these 2 factors, $\mathrm{Hb} \geq 10 \mathrm{~g} / \mathrm{dL}$ and eGFR $\geq 60 \mathrm{~mL} /$ $\left(\min \cdot 1.73 \mathrm{~m}^{2}\right) ; \mathrm{Hb} \geq 10$ or eGFR $\geq 60$; and $\mathrm{Hb}<10$ and eGFR $<60$, overall survival curves were significantly different (Figure 3, $p=0.002$ ), with 1-year overall survival rates of $60 \%, 17 \%$, and $0 \%$, respectively, and median survival rates of $16.9,8.6$, and 5.4 months, respecttively.

\subsection{Association of the Two Prognostic Factors with the Cycles and Amount of PCG}

There was no difference between $\mathrm{Hb}$, eGFR, and the total number of PCG courses (Figure 4(a)). Besides, no statistical difference was observed between $\mathrm{Hb}$, eGFR, and the average dose of PCG, although the average dose of the group with $\mathrm{Hb} \geq 10 \mathrm{~g} / \mathrm{dL}$ and eGFR $\geq 60$ $\mathrm{mL} /\left(\min \cdot 1.73 \mathrm{~m}^{2}\right)$ tended to be close to the full dose (Figure 4(b)).

\section{DISCUSSION}

We reported the results of 25 patients undergoing PCG therapy as a second-line treatment for UCs. Although this second-line regimen had a modest clinical effect with a response rate of $24 \%$ and 8.5 months overall survival, a longer survival of 16.9 months was observed in the selected patients. The clinical parameters of these patients revealed no anemia $(\mathrm{Hb} \geq 10 \mathrm{~g} / \mathrm{dL})$ and sufficient renal function $\left(\mathrm{eGFR} \geq 60 \mathrm{~mL} /\left(\min \cdot 1.73 \mathrm{~m}^{2}\right)\right.$ ).

This is the first study that shows the limited but potential clinical benefits of second-line PCG therapy in the treatment of UCs.

PCG therapy was first introduced as a highly active first-line regimen in 2000, with a high response rate of $78 \%$ and prolonged median overall survival of 24 months [10]. A follow-up multicenter phase 2 study showed shorter but good median survival of 15.6 months [18]. Moreover, a recent randomized phase III study comparing PCG and GC demonstrated that PCG provided a bet-

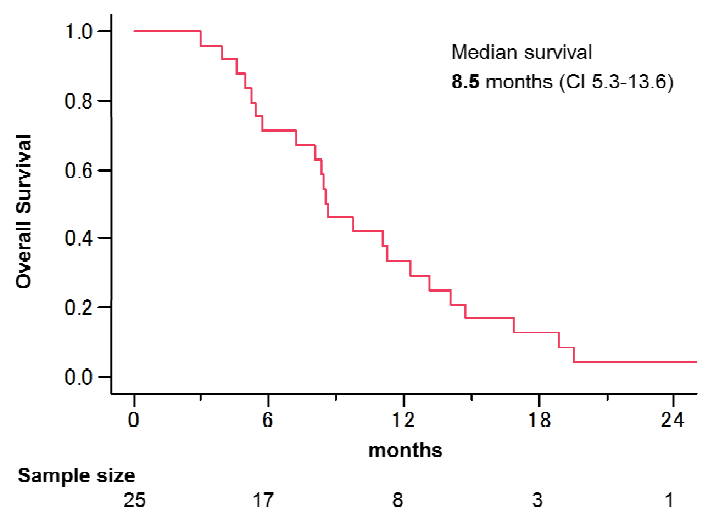

Figure 2. Kaplan-Meier survival curves of overall survival. Median survival was 8.5 months. 
Table 4. Univariate and multivariate analysis for overall survival.

\begin{tabular}{|c|c|c|c|c|c|c|}
\hline \multirow{2}{*}{ Parameters } & \multicolumn{2}{|l|}{ Univariate } & \multicolumn{2}{|c|}{ Multivariate (full model) } & \multicolumn{2}{|c|}{ Multivariate (reduced model) } \\
\hline & HR $(95 \%$ CI) & $p$ & HR $(95 \%$ CI) & $p$ & HR $(95 \%$ CI) & $p$ \\
\hline Age $\geq 65$ & $0.96(0.42-2.24)$ & 0.932 & - & - & - & - \\
\hline Female sex & $0.97(0.32-2.46)$ & 0.950 & - & - & - & - \\
\hline ECOG performance status $\geq 1$ & $1.41(0.40-3.85)$ & 0.556 & - & - & - & - \\
\hline Charlson-Romano Index score $\geq 1$ & $1.15(0.43-2.82)$ & 0.762 & - & - & - & - \\
\hline Previous definitive surgery & $1.20(0.48-3.42)$ & 0.705 & - & - & - & - \\
\hline $\begin{array}{l}\text { Previous cumulative dose of cisplatin } \\
\qquad 200 \mathrm{mg}\end{array}$ & $1.12(0.48-2.66)$ & 0.799 & - & - & - & - \\
\hline Upper urinary tract origin & $0.56(0.24-1.37)$ & 0.198 & - & - & - & - \\
\hline Mixed UC histology & $1.92(0.29-7.70)$ & 0.442 & - & - & - & - \\
\hline No. of sites of disease $\geq 2$ & $1.61(0.65-4.57)$ & 0.311 & - & - & - & - \\
\hline Visceral metastasis & $1.25(0.46-4.40)$ & 0.684 & - & - & - & - \\
\hline Liver metastasis & $3.49(1.08-9.78)$ & $0.038^{*}$ & $3.04(0.92-8.81)$ & 0.066 & - & - \\
\hline Bone metastasis & $1.93(0.81-4.69)$ & 0.138 & - & - & - & - \\
\hline Hemoglobin $<10 \mathrm{~g} / \mathrm{dL}$ & $4.21(1.55-11.60)$ & $0.005^{*}$ & $4.19(1.50-11.89)$ & $0.007^{*}$ & $4.08(1.51-11.19)$ & $0.006^{*}$ \\
\hline C-reactive protein $>0.5 \mathrm{mg} / \mathrm{dL}$ & $1.19(0.33-3.39)$ & 0.061 & - & - & - & - \\
\hline Creatinine clearance $<60 \mathrm{~mL} / \mathrm{min}$ & $1.80(0.77-4.32)$ & 0.176 & - & - & - & - \\
\hline eGFR $<60 \mathrm{~mL} /\left(\min \cdot 1.73 \mathrm{~m}^{2}\right)$ & $2.91(1.09-9.25)$ & $0.032^{*}$ & $2.85(1.07-9.07)$ & $0.036^{*}$ & $2.83(1.06-9.01)$ & $0.038^{*}$ \\
\hline
\end{tabular}

ECOG, Eastern Cooperative Oncology Group; UC, urothelial carcinoma; eGFR, estimated glomerular filtration rate; ${ }^{*} p<0.05$.

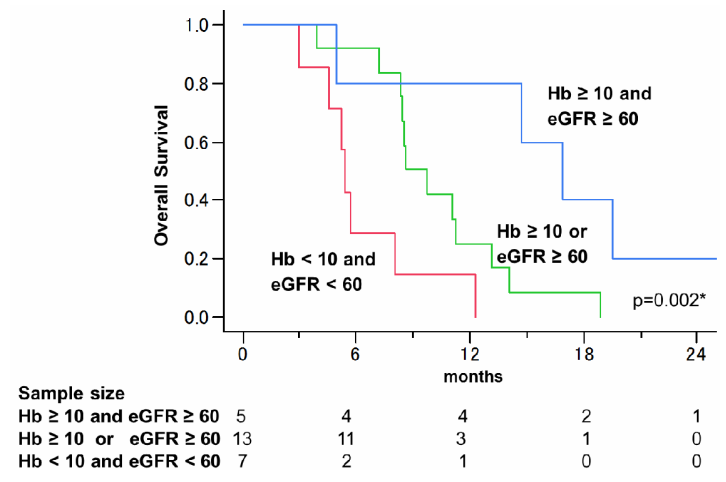

Figure 3. Overall survival curves stratified by $\mathrm{Hb}$ and eGFR values. When stratified into the 3 groups $(\mathrm{Hb} \geq$ $10 \mathrm{~g} / \mathrm{dL}$ and $\mathrm{eGFR} \geq 60 \mathrm{~mL} /\left(\min \cdot 1.73 \mathrm{~m}^{2}\right), \mathrm{Hb} \geq 10$ or eGFR $\geq 60$, and $\mathrm{Hb}<10$ and eGFR $<60$ ), overall survival curves were significantly different $(p=0.002)$, and median survivals were $16.9,8.6$, and 5.4 months.

ter response rate and a 3 months longer median survival compared to GC alone, although the differences did not reach statistical significance [11]. However, although the efficacy and safety of PCG as a first-line treatment have been demonstrated, there is no information about the efficacy of PCG regimen as a second-line treatment. In the current study, we found that patients with anemia and insufficient renal function had unfavorable survival. The hypoactive bone marrow and renal function may have

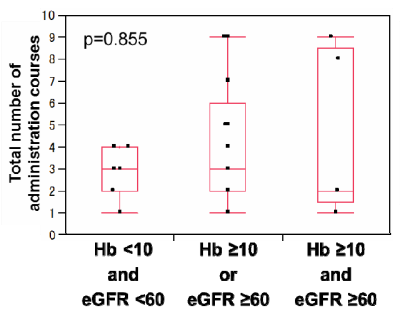

(a)

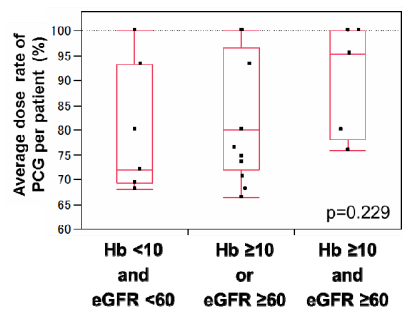

(b)
Figure 4. Total number of PCG administration courses (a) and average doses of PCG (b) in patients stratified by $\mathrm{Hb}$ and eGFR $\left(\mathrm{Hb} \geq 10 \mathrm{~g} / \mathrm{dL}\right.$ and eGFR $\geq 60 \mathrm{~mL} /\left(\min \cdot 1.73 \mathrm{~m}^{2}\right), \mathrm{Hb} \geq 10$ or eGFR $\geq 60$, and $\mathrm{Hb}<10$ and eGFR $<60$ ). The differences were not statistically significant for the total number of courses and for the average dose.

simply prevented the patients from receiving sufficient chemotherapy. However, there was no difference between $\mathrm{Hb}$, eGFR, and the total number of PCG courses. Besides, no statistical difference was observed between $\mathrm{Hb}$, eGFR, and the average dose of PCG, although the average dose of the group with no anemia and sufficient renal function tended to be close to the full dose. According to these results, second-line PCG might be beneficial especially for the patients with no anemia and sufficient renal function.

Several studies in the literature reported the identification of prognostic factors for survival with second-line 
chemotherapy. Bellmunt et al., showed that the presence of liver metastasis, poor ECOG-PS, and low Hb levels were significant risk factors for poor prognosis in patients with second-line vinflunine monotherapy [19]. Similarly, Saito et al., reported ECOG-PS, number of mestatic sites, and serum C-reactive protein levels to be sigficant risk factors for prognosis in patients undergoing second-line chemotherapy with gemcitabine, etoposide, and cisplatin [20]. In our study, $\mathrm{Hb}$ and eGFR values reined significant risk factors after multivariate analysis. Our finding on $\mathrm{Hb}$ levels was consistent with a previous report [19]. eGFR was acceptable as a prognostic factor because serum creatinine level is a well-known prognostic factor for survival in patients treated with radical cystectomy for UC [21]. eGFR remained a prognostic factor and not Ccr, probably because Ccr is known to be falsely higher than the actual GFR [22].

Our study has some limitations. First, it was a retrospective study performed in a single institution and with a small cohort of patients. Ideally, a multicenter and large cohort study will be required to confirm our results. Second, because GC regimen is being used widely as first-line setting instead of M-VAC [3], PCG, which uses two of the same drugs as GC, is rarely considered a candidate for second-line treatment after first-line GC therapy. Second-line PCG could represent a limited alternative until more effective and less toxic first-line treatments become available. However, the PCG regimen is still a possible treatment option for advanced UCs, and a recent randomized phase III trial reported that PCG had produced significant survival benefit in an adjuvant setting [23]. Therefore, our results provide useful information in order to understand the potential of the PCG regimen comprehensively.

In conclusion, PCG chemotherapy achieved good responses in a selected group of patients with advanced UCs after failure of first-line cisplatin-based regimens with relatively significant but tolerable toxicity. Regimens that are more effective and less toxic should be explored for standard second-line treatments.

\section{REFERENCES}

[1] Loehrer, P.J., Sr, Einhorn, L.H., Elson, P.J., Crawford, E.D., Kuebler, P., Tannock, I., et al. (1992) A randomized comparison of cisplatin alone or in combination with methotrexate, vinblastine, and doxorubicin in patients with metastatic urothelial carcinoma: A cooperative group study. Journal of Clinical Oncology, 10, 1066-1073.

[2] Saxman, S.B., Propert K.J., Einhorn, L.H., Crawford, E.D., Tannock, I., Raghavan, D., et al. (1997) Long-term follow-up of a phase III intergroup study of cisplatin alone or in combination with methotrexate, vinblastine, and doxorubicin in patients with metastatic urothelial carcinoma: A cooperative group study. Journal of Clinical
Oncology, 15, 2564-2569.

[3] von der Maase, H., Sengelov, L., Roberts, J.T., Ricci, S., Dogliotti, L., Oliver, T., et al. (2005) Long-term survival results of a randomized trial comparing gemcitabine plus cisplatin, with methotrexate, vinblastine, doxorubicin, plus cisplatin in patients with bladder cancer. Journal of Clinical Oncology, 23, 4602-4608. doi:10.1200/JCO.2005.07.757

[4] Sternberg, C.N., Calabrò, F., Pizzocaro, G., Marini, L., Schnetzer, S., Sella, A. (2001) Chemotherapy with an every-2-week regimen of gemcitabine and paclitaxel in patients with transitional cell carcinoma who have received prior cisplatin-based therapy. Cancer, 92, 29932998.

doi:10.1002/1097-0142(20011215)92:12<2993::AID-CN CR10108>3.0.CO;2-2

[5] Fechner, G., Siener, R., Reimann, M., Kobalz, L., Albers, P. (2006) Randomised phase II trial of gemcitabine and paclitaxel second-line chemotherapy in patients with transitional cell carcinoma (AUO Trial AB 20/99). The International Journal of Clinical Practice, 60, 27-31. doi:10.1111/j.1742-1241.2005.00663.x

[6] Matsumoto, K., Irie, A., Satoh, T., Okazaki, M., Iwamura, M., Baba, S. (2007) Gemcitabine and paclitaxel chemotherapy as a second-line treatment for advanced or metastatic urothelial carcinoma. International Journal of Urology, 14, 1000-1004.

[7] Kanai, K., Kikuchi, E., Ohigashi, T., Miyajima, A., Nakagawa, K., Nakashima, J., et al. (2008) Gemcitabine and paclitaxel chemotherapy for advanced urothelial carcinoma in patients who have received prior cisplatin-based chemotherapy. International Journal of Clinical Oncology, 13, 510-514. doi:10.1007/s10147-008-0779-x

[8] Culine, S., Theodore, C., De Santis, M., Bui, B., Demkow, T., Lorenz, J., et al. (2006) A phase II study of vinflunine in bladder cancer patients progressing after first-line platinum-containing regimen. British Journal of Cancer, 94, 1395-1401. doi:10.1038/sj.bjc.6603118

[9] Bellmunt, J., Théodore, C., Demkov, T., Komyakov, B., Sengelov, L., Daugaard, G., et al. (2009) Phase III trial of vinflunine plus best supportive care compared with best supportive care alone after a platinum-containing regimen in patients with advanced transitional cell carcinoma of the urothelial tract. Journal of Clinical Oncology, 27, 4454-4461. doi:10.1200/JCO.2008.20.5534

[10] Bellmunt, J., Guillem, V., Paz-Ares, L., González-Larriba, J.L., Carles, J., Batiste-Alentorn, E., et al. (2000) Phase I - II study of paclitaxel, cisplatin, and gemcitabine in advanced transitional-cell carcinoma of the urothelium. Jourrnal of Clinical Oncology, 18, 3247-3255.

[11] Bellmunt, J., von der Maase, H., Mead, G.M., Skoneczna, I., De Santis, M., Daugaard, G., et al. (2012) Randomized phase III study comparing paclitaxel/cisplatin/gemcitabine and gemcitabine/cisplatin in patients with locally advanced or metastatic urothelial cancer without prior systemic therapy: EORTC Intergroup Study 30987. Journal of Clinical Oncology, 30, 1107-1113.

[12] Charlson, M.E., Pompei, P., Ales, K.L., MacKenzie, C.R. (1987) A new method of classifying prognostic comor- 
bidity in longitudinal studies: Development and validation. Journal of Chronic Diseases, 40, 373-383.

[13] Romano, P.S., Roos, L.L., Jollis, J.G. (1993) Adapting a clinical comorbidity index for use with ICD-9-CM administrative data: Differing perspectives. Journal of Clinical Epidemiology, 46, 1075-1079.

[14] Matsuo, S., Imai, E., Horio, M., Yasuda, Y., Tomita, K., Nitta, K., et al. (2009) Revised equations for estimated GFR from serum creatinine in Japan. American Journal of Kidney Diseases, 53, 982-992. doi:10.1053/j.ajkd.2008.12.034

[15] Therasse, P., Arbucl, S.G., Eisenhauer, E.A., Wanders, J., Kaplan, R.S., Rubinstein, L., et al. (2000) New guidelines to evaluate the response to treatment in solid tumors. Journal of the National Cancer Institute. 92, 205-216.

[16] Fukui, I., Yonese, J., Tsukamoto, T., Yoshida, T., Kim, T., Tohma, T., et al. (2001) Combination chemotherapy with ifosfamide, 5-fluorouracil, etoposide and cisplatin for memtastatic urothelial cancer. Cancer Chemotherapy and Pharmacology, 48, 88-93.

[17] Tatokoro, M., Kawakami, S., Yonese, J., Fujii, Y., Okubo, Y., Yamamoto, S., et al. (2008) Preliminary report of multimodal treatment with ifosfamide, 5-fluorouracil, etoposide and cisplatin (IFEP chemotherapy) against metastatic adenocarcinoma of the urachus. International Journal of Urology, 15, 851-853. doi:10.1111/j.1442-2042.2008.02113.x

[18] Bellmunt, J., Albanell, J., Paz-Ares, L., Climent, M.A., González-Larriba, J.L., Carles, J., et al. (2002) Pretreatment prognostic factors for survival in patients with advanced urothelial tumors treated in a phase I/II trial with paclitaxel, cisplatin, and gemcitabine. Cancer, 95, 751757. doi: $10.1002 /$ cncr. 10762
[19] Bellmunt, J., Choueiri, T.K., Fougeray, R., Schutz, F.A., Salhi, Y., Winquist, E., et al. (2010) Prognostic factors in patients with advanced transitional cell carcinoma of the urothelial tract experiencing treatment failure with platinum-containing regimens. Journal of Clinical Oncology, 28, 1850-1855. doi:10.1200/JCO.2009.25.4599

[20] Saito, K., Urakami, S., Komai, Y., Yasuda, Y., Kubo, Y., Kitsukawa, S., et al. (2012) Impact of C-reactive protein kinetics on survival of patients with advanced urothelial carcinoma treated by second-line chemotherapy with gemcitabine, etoposide and cisplatin. BJU International, 110 1478-1484. doi:10.1111/j.1464-410X.2012.11153.x

[21] Thrasher, J.B., Frazier, H.A., Robertson, J.E., Dodge, R.K., Paulson, D.F. (1994) Clinical variables which serve as predictors of cancer-specific survival among patients treated with radical cystectomy for transitional cell carcinoma of the bladder and prostate. Cancer, 73, 17081715 .

doi:10.1002/1097-0142(19940315)73:6<1708::AID-CNC R2820730626>3.0.CO;2-J

[22] Orita, Y., Gejyo, F., Sakatsume, M., Shiigai, T., Maeda, Y., Imai, E., et al. (2005) Estimation of glomerular filtration rate by inulin clearance: comparison with creatinine clearance (article in Japanese). Nihon Jinzo Gakkai Shi, 47, 804-812.

[23] Paz-Ares, L.G., Solsona, E., Esteban, E., Saez, A., Gonzalez-Larriba, J., Anton, A., et al. (2010) Randomized phase III trial comparing adjuvant paclitaxel/gemcitabine/cisplatin (PGC) to observation in patients with resected invasive bladder cancer: Results of the Spanish Oncology Genitourinary Group (SOGUG) 99/01 study. Journal of Clinical Oncology, 28, 18s. 